\title{
Learning and Shifts in Long-Run Productivity Growth
}

\author{
Rochelle M. Edge, Thomas Laubach, and John C. Williams*
}

April 2, 2004

*Board of Governors of the Federal Reserve System, rochelle.m.edge@frb.gov; Board of Governors of the Federal Reserve System and OECD, thomas.laubach@oecd.org; and Federal Reserve Bank of San Francisco, john.c.williams@sf.frb.org (corresponding author). We thank Michael Dotsey, John Fernald, Andreas Hornstein, Spencer Krane, Eric Leeper, Ed Nelson, Dave Reifschneider, Glenn Rudebusch, Tom Sargent, Argia Sbordone, Stephanie Schmitt-Grohe, Michael Woodford, Raf Wouters, and participants at numerous presentations for comments on earlier versions of this paper. We also thank Kirk Moore for excellent research assistance and Judith Goff for editorial assistance. The views expressed herein are those of the authors and do not necessarily reflect those of the Board of Governors of the Federal Reserve System or their staff, the management of the Federal Reserve Bank of San Francisco, or the OECD. 


\begin{abstract}
Shifts in the long-run rate of productivity growth - such as those experienced by the U.S. economy in the 1970s and 1990s - are difficult, in real time, to distinguish from transitory fluctuations. In this paper, we analyze the evolution of forecasts of longrun productivity growth during the 1970s and 1990s and examine in the context of a dynamic general equilibrium model the consequences of gradual real-time learning on the responses to shifts in the long-run productivity growth rate. We find that a simple updating rule based on an estimated Kalman filter model using real-time data describes economists' long-run productivity growth forecasts during these periods extremely well. We then show that incorporating this process of learning has profound implications for the effects of shifts in trend productivity growth and can dramatically improve the model's ability to generate responses that resemble historical experience. If immediately recognized, an increase in the long-run growth rate causes long-term interest rates to rise and produces a sharp decline in employment and investment, contrary to the experiences of the 1970s and 1990s. In contrast, with learning, a rise in the long-run rate of productivity growth sets off a sustained boom in employment and investment, with long-term interest rates rising only gradually. We find the characterization of learning to be crucial regardless of whether shifts in long-run productivity growth owe to movements in TFP growth concentrated in the investment goods sector or economy-wide TFP.
\end{abstract}

JEL Codes: E13, E32, D83, O40.

Keywords: DGE models, Kalman-filter, Real-time data, Learning, Productivity growth. 


\section{Introduction}

An extensive literature has studied the effects of shocks to the level of productivity in dynamic general equilibrium models. Surprisingly, despite the attention that has been paid to documenting and understanding the 1970s productivity slowdown and the 1990s acceleration, there has been relatively little formal analysis in the DGE framework on the effects of a sustained shift in the rate of growth of productivity. ${ }^{1}$ A notable exception is Campbell (1994), who found that in a real business cycle model a highly persistent reduction in the productivity growth rate yielded the "perverse" response of a rise in employment and output (see also the recent paper by Pakko, 2002). ${ }^{2}$ This result seems at odds with the conventional wisdom that the productivity slowdown in the 1970s contributed to the woeful macroeconomic performance of that decade and that the productivity acceleration of the 1990s was a central factor behind the remarkable performance in the late 1990s (Blinder and Yellen 2002).

Research on the effects of a shift in long-run productivity growth has tended to assume that agents immediately recognize the nature of such a shock and modify their expectations and actions accordingly. In practice, sizable transitory fluctuations in productivity growth obscure one's view of the underlying trend growth rate. As a result, it takes years for even professional economists to recognize that a shift has occurred, as evidenced by the debate about the nature of the productivity slowdown during the 1970s and the acceleration in the 1990s. In 1997, for example, Blinder (1997) placed the trend rate of labor productivity growth at 1.1 percent, consistent with the average pace of productivity growth over the preceding 23 years. Two years later, Gordon (1999) estimated trend productivity growth to be 1.85 percent, a figure that he revised up to 2.25 percent in 2000 (in part due to methodological changes in the national income accounts), and again to 2.5 percent in 2003

\footnotetext{
${ }^{1}$ Studies that provide early analysis of the causes of the productivity slowdown in the 1970s include Denison (1979) and Norsworthy, Harper, and Kunze (1979), and the references cited therein. Jorgenson and Stiroh (2000), Oliner and Sichel (2000), Basu, Fernald, and Shapiro (2001), and Gordon (2003) examine the sources of the pickup in productivity growth in the 1990s.

${ }^{2}$ Other exceptions include include Brayton and Reifschneider (2001), who study the effects of a shift in the long-run rate of productivity growth using the Federal Reserve Board's large-scale macroeconometric model, and Braun (1984) and Ball and Moffitt (2001), who study the effects on inflation in reduced-form models.
} 
(see Gordon 1999, 2000, 2003). As shown in this paper, this pattern of gradual learning about shifts in long-run growth rate applies to both the 1970s and 1990s episodes.

In this paper we examine real-time estimates of trend productivity growth and compare these to the predictions of a simple linear updating rule based on an estimated Kalman filter model. We document that projections of long-run growth by economists and professional forecasters adjust only gradually to this type of structural change: In the 1990s, for example, the long-run productivity growth rate picked up significantly around the middle of the decade, however, as noted above and documented below, the corresponding estimates by economists and professional forecasters changed little until 1999 and shot up dramatically in 2000 .

We find that the real-time predictions of an estimated Kalman filter model track closely the year-to-year movements in long-run expectations during both the 1970s and the 1990s. Although economists use a wide variety of methods to estimate long-run trends, as discussed by Lansing (2000), a simple linear updating rule approximates these methods extremely well. Our model forecasts are constructed using a real-time dataset of labor productivity that we collected. We show that the use of real-time data is crucial for understanding the historical evolution of long-run expectations. ${ }^{3}$ Data revisions were especially pronounced during the late 1990s, and they shaped the pattern of long-run expectations at the time.

We then examine the effects of learning regarding long-run productivity growth on the responses to shifts in the trend growth rate in a standard optimization-based dynamic general equilibrium model. Following on the results of Cummins and Violante (2002), who emphasize the importance in the 1990s of shifts in the growth rate of productivity in the investment-goods sector, we analyze shifts both to aggregate total factor productivity (TFP) and to TFP in the investment goods sector alone. We calibrate the learning rate to be consistent with the Kalman filter estimates and the survey evidence of long-run expectations. We assume that agents in the model economy use the same Kalman filter updating formula for long-run productivity growth that we found fits the survey data. One criticism of this assumption is that agents may have greater information regarding their own idiosyncratic economic prospects than the macroeconomic forecasters have about the aggregate rate of productivity. Nonetheless, the expected future trajectory of any individual's wages and rates

\footnotetext{
${ }^{3}$ Our results are similar in spirit to those of Orphanides (2001) who examined the role of data revisions in analyzing historical monetary policy.
} 
of return depend on the aggregate level of wages and rates of return. Thus, in forecasting the common component of wages and rates of return, agents face the same signal extraction problem as macroeconomic forecasters.

We find that gradual recognition through learning has profoundly different implications from immediate recognition for the economic effects of a shift in trend productivity growth. ${ }^{4}$ With gradual recognition through learning, we find that a permanent increase in the rate of productivity growth boosts hours and investment at the onset of the shock and leads to a sustained boom in employment and output growth. Under these learning assumptions, agents initially believe that the shock is mainly transitory in nature and therefore has minimal long-run implications for interest rates and the capital stock. As a result, the stimulative effects of high productivity on employment and investment dominate and a sustained boom ensues. In addition, with learning, long-term real bond rates rise only gradually in response to a productivity acceleration, consistent with the evidence from the late 1990s. In contrast, with immediate recognition, we obtain Campbell's "perverse" effects; specifically, a rise in long-run productivity growth elicits a rise in the natural rate of interest. The resulting rise in real rates reduces the optimal ratio of capital to output, implying that the existing stock of capital is too high. The productivity acceleration and the implied capital overhang then generate a sharp decline in investment and employment.

The paper is organized as follows. Section 2 examines the evidence on real-time estimates of long-run productivity growth during the 1970s and 1990s. Section 3 describes a simple Kalman filter model and compares its real-time predictions of long-run productivity to evidence from surveys and other documents. Section 4 describes both our optimization-based dynamic general equilibrium model and the nonlinear model solution method. Section 5 analyzes the steady-state and dynamic implications of shifts in the growth rates of aggregate and investment goods sector TFP. Section 6 concludes.

\section{Real-time Estimates of Long-Run Productivity Growth}

In this section, we document the real-time evolution of expectations of long-run productivity growth during the 1970s and the 1990s, two periods during which the actual trend shifted

\footnotetext{
${ }^{4}$ This paper focusses on the implications for the real side of the economy. In Edge, Laubach, and Williams (2003), we further examine the implications of gradual recognition of a shift in long-run productivity growth on prices and monetary policy.
} 
Figure 1: Labor Productivity Growth

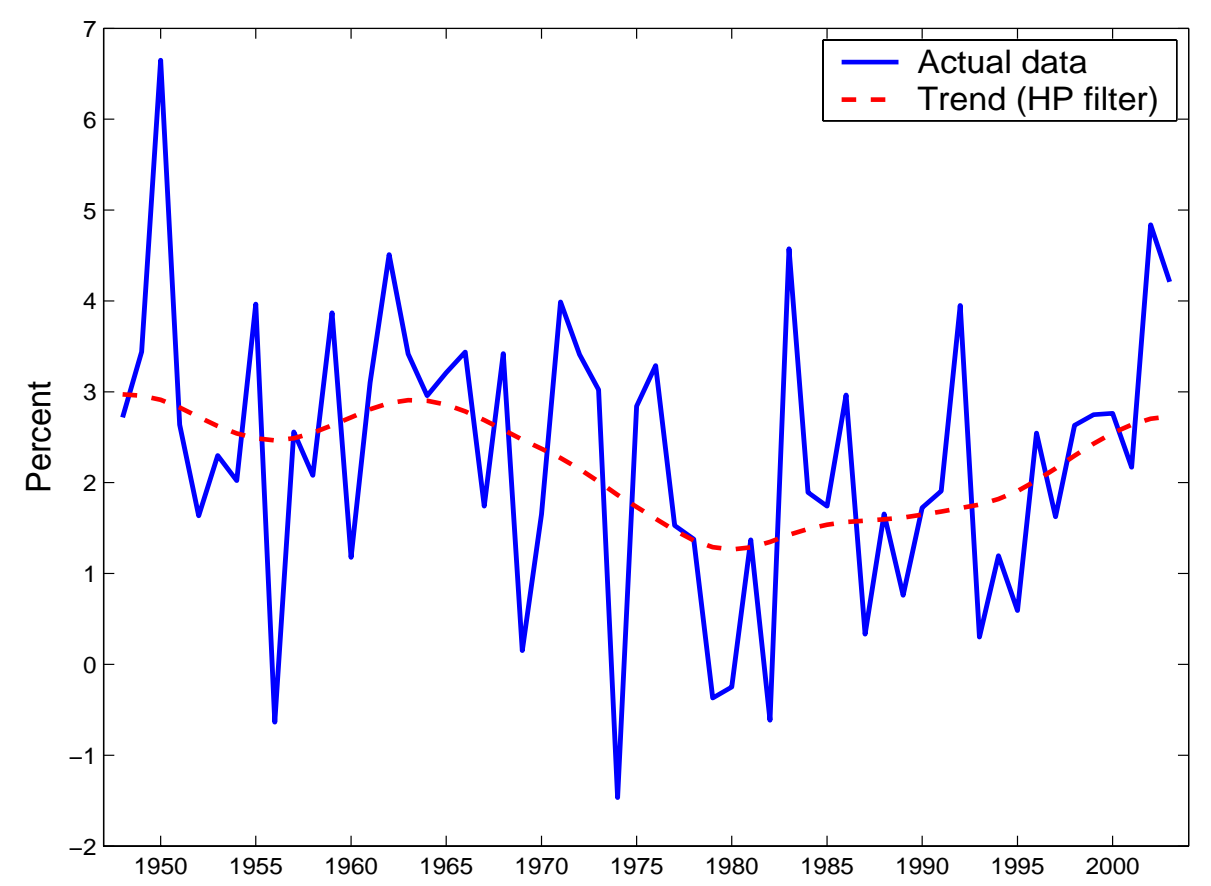

dramatically. Throughout this paper, we focus on labor productivity, as opposed to total factor productivity (TFP), because there exist little historical data on real-time estimates of long-run TFP growth with which to compare our model.

\subsection{Shifts in Long-Run Productivity Growth}

The "trend" rate of productivity growth has fluctuated significantly over the past 50 years; however, these movements are dwarfed by the year-to-year transitory fluctuations in the rate of productivity growth. The solid line in Figure 1 shows the annual growth rate of labor productivity (output per hour) in the nonfarm business sector for 1948-2003; the dashed line shows a retrospective estimate of trend productivity growth constructed using the HP filter (with a smoothing parameter of 100). The trend line shows that labor productivity growth was about 3 percent on average through the mid-1960s, slowed to $1-1 / 2$ percent in the 1970s, and rose again to nearly 3 percent in the late 1990s and early in the 21st century.

Statistical tests provide evidence of variation in long-run productivity growth. An Andrews-Lee-Ploberger (1996) test for a single break in the growth rate of nonfarm labor 
Table 1: Real-time Estimates of Long-Run Productivity Growth, 1995-2004

\begin{tabular}{lrrrrrrrrrr}
\hline & \multicolumn{10}{c}{ Vintage of Estimate (January/February) } \\
\cline { 2 - 11 } & 1995 & 1996 & 1997 & 1998 & 1999 & 2000 & 2001 & 2002 & 2003 & 2004 \\
\hline CBO & 1.3 & 1.2 & 1.2 & 1.5 & 1.8 & 2.3 & 2.7 & 2.2 & 2.2 & 2.2 \\
CEA & 1.2 & 1.2 & 1.2 & 1.3 & 1.3 & 2.0 & 2.3 & 2.1 & 2.1 & 2.1 \\
SPF & 1.6 & 1.5 & 1.4 & 1.5 & 1.7 & 2.4 & 2.5 & 2.2 & 2.4 & 2.6 \\
Change from 1995 & & & & & & & & & & \\
CBO & - & -.1 & -.1 & .2 & .5 & 1.0 & 1.4 & .9 & .9 & .9 \\
CEA & - & .0 & .0 & .1 & .1 & .8 & 1.1 & .9 & .9 & .9 \\
SPF & - & -.1 & -.2 & -.1 & .1 & .8 & .9 & .6 & .8 & 1.0 \\
\hline \hline
\end{tabular}

productivity yields a p-value of about 10 percent for the null of no break; the corresponding p-value for business sector productivity (which includes the agricultural sector) is only about 1 percent. In addition, a number of researchers have found evidence of time variation in the trend GDP growth rate using the Kalman filter (Stock and Watson 1998; Brainard and Perry 2000; Roberts 2001; Gordon 2003; and Laubach and Williams 2003). Finally, Kahn and Rich (2003) estimate a Markov switching model for trend growth and find strong evidence for two states corresponding to "low" and "high" growth rates.

Although swings in the long-run rate of productivity growth seem relatively clear in hindsight, they are hard to identify in real time because they are clouded by transitory movements in productivity growth. The standard deviation of productivity growth is about equal to the magnitude of the shifts that occurred in the early 1970s and the mid-1990s. In addition, as shown below, data revisions further hinder the problem of identifying shocks. We now examine the real-time estimates of trend productivity growth taken from published sources.

\subsection{Forecasts of Long-run Productivity Growth}

Table 1 reports the real-time estimates of long-run labor productivity growth reported by the Congressional Budget Office (CBO) in its annual Budget and Economic Outlook, the Council of Economic Advisors (CEA) in the annual Economic Report of the President (ERP) published in January or February each year, and the mean estimate from the February report of the Survey of Professional Forecasters (SPF). A description of the data sources and the 
data series themselves are provided in the Appendix. ${ }^{5}$ The three series follow the same pattern over this period. The differences in levels across the surveys may in part reflect differences in concepts of labor productivity. ${ }^{6}$

Real-time estimates of long-run productivity growth adjusted only gradually to the shift in underlying trend productivity growth during the 1990s. They dipped a bit in 1997, and edged up in each of the next two years. Then, in 2000, they shot up, increasing by 0.5 percentage point $(\mathrm{CBO})$ and 0.7 percentage point (CEA and SPF), after which they fell following the 2001 recession. Compared to real-time estimates in 1995, the 2004 vintage real-time estimates were up about 1 percentage point.

Hard data on real-time estimates of long-run productivity growth during the 1970s are more difficult to come by; still, the available evidence indicates that economists only gradually recognized the occurrence of the slowdown and only after five years or so fully appreciated its magnitude. The CEA is the single source that approaches that of a consistent time series. Table 2 reports real-time estimates of trend productivity growth from the ERP for those years between 1970 and 1980 that such estimates were reported or could be directly inferred from the text of the Report and supporting documents.

During the 1970s, the CEA revised down its forecasts of trend productivity growth in a series of steps. In early 1970, its estimate of trend productivity growth in the entire economy was 2.8 percent; in 1974, it revised the estimate down 0.4 percentage point; in 1977 the estimate was revised down another 0.3 percentage point and then a further 0.6 percentage point in 1979. The revisions in 1977 and 1979 were accompanied by detailed discussions in the ERP outlining the CEA's reassessments of long-run productivity and output trends. ${ }^{7}$

\footnotetext{
${ }^{5}$ As noted in the Appendix, only the CEA provides a reasonably consistent time series of medium-run productivity projections that starts before the early 1990s. Explicit estimates from the CBO first appear in the mid-1990s, and the SPF first started asking a question on long-run productivity growth in 1992.

${ }^{6}$ The projections reported by the $\mathrm{CBO}$ and CEA during this period explicitly refer to output per hour in the nonfarm business sector, while the SPF survey simply refers to productivity growth. Productivity growth can differ according to the measure used; for example, output per hour in the overall business sector averaged 0.2 percentage points higher than that in the nonfarm business sector during 1973-1995 (according to data available in early 1996), which is about the difference between the SPF and CBO estimates of long-run productivity growth in 1996.

${ }^{7}$ See also Clark (1978), a staff member at the CEA at the time, who provides a detailed analysis of the evidence for and causes of the productivity slowdown. By comparison, Perry (1977) remained very optimistic about productivity's trend growth rate in 1977. It was not until the late 1970s that a consensus
} 
Table 2: CEA Real-time Forecasts of Trend Productivity Growth, 1970-1980

\begin{tabular}{|c|c|c|c|c|c|c|c|c|c|c|}
\hline \multicolumn{11}{|c|}{ Vintage of Estimate (January/February) } \\
\hline 1970 & 1971 & 1972 & 1973 & 1974 & 1975 & 1976 & 1977 & 1978 & 1979 & 1980 \\
\hline 2.8 & 2.8 & - & - & 2.4 & - & - & 2.1 & 2.1 & 1.5 & 1.5 \\
\hline \multicolumn{11}{|c|}{ Change from 1970} \\
\hline- & .0 & - & - & -.4 & - & - & -.7 & -.7 & -1.3 & -1.3 \\
\hline $\begin{array}{l}\text { Note } \\
\text { indic }\end{array}$ & $\begin{array}{l}\text { Obs } \\
\text { d ye }\end{array}$ & $\begin{array}{l}\text { ration } \\
\text { (the }\end{array}$ & $\begin{array}{l}\text { are } \mathrm{f} \\
72,1\end{array}$ & $\begin{array}{l}n E c c \\
3,197\end{array}$ & $\begin{array}{l}m i c \\
\text { and }\end{array}$ & $\begin{array}{l}\text { eport } \\
976 \text { i }\end{array}$ & $\begin{array}{l}f \text { of } t \\
\text { les di }\end{array}$ & $\begin{array}{l}\text { Pres } \\
\text { ot } r\end{array}$ & $\begin{array}{l}n t \text { of } \\
\text { rt es }\end{array}$ & tes) \\
\hline
\end{tabular}

By the end of the decade, the estimate had fallen 1.3 percentage point to 1.5 percent.

The evidence from real-time estimates indicates that professional economists only gradually recognized the occurrence and extent of the productivity slowdown of the 1970s and the acceleration during the 1990s. Indeed, full adjustment to the new trend rate of growth appears to have taken many years. We now examine whether the observed pattern of longrun expectations can be explained by a standard signal extraction model using real-time data.

\section{Estimating Long-Run Productivity Growth}

We now formalize the problem of estimating the trend growth rate by filtering out transitory fluctuations from observed productivity. As noted above, shifts in the trend growth rate of productivity appear to be infrequent, while year-to-year swings in productivity growth are common. A frequently used tool for estimating the trend growth rate of productivity or output is the Kalman filter (Stock and Watson 1998, Brainard and Perry 2000, Roberts 2001, Laubach and Williams 2003). A key advantage of the Kalman filter is that under a particular set of assumptions regarding the data generating processes for productivity growth, it reduces to a simple linear updating formula for estimating the trend rate of productivity growth.

regarding a productivity slowdown in the 1970s began to form among academic economists (see Denison 1979, Norsworthy, Harper, and Kunze 1979, and references therein.) 


\subsection{The Kalman Filter}

Consider the following stylized model of transitory and permanent components of labor productivity growth. Denote the level of labor productivity by $P_{t}$, and its trend gross growth rate by $G_{p, t}$, and define the log-level of labor productivity as $p_{t}\left(=\ln P_{t}\right)$ and the trend net growth rate as $g_{p, t}\left(=\ln G_{p, t}\right)$. Let the stochastic laws of motion for $p_{t}$ and $g_{p, t}$ be given by

$$
\begin{aligned}
p_{t} & =p_{t-1}+g_{p, t}+\epsilon_{t}, & \epsilon_{t} & \sim N\left(0, \sigma_{\epsilon}^{2}\right), \\
g_{p, t} & =g_{p, t-1}+\nu_{t}, & \nu_{t} & \sim N\left(0, \sigma_{\nu}^{2}\right),
\end{aligned}
$$

where the disturbances $\epsilon_{t}$ and $\nu_{t}$ are assumed to be serially uncorrelated with Gaussian distribution and zero contemporaneous correlation. ${ }^{8}$ The disturbance $\epsilon_{t}$ corresponds to a permanent shock to the level of productivity, while $\nu_{t}$ is a shock to the trend growth rate of productivity. We do not claim that this is a correctly specified model of the data generating process for labor productivity growth, but instead view this specification as a parsimonious and tractable approximation to a variety of data generating processes for highly persistent shifts in the trend growth rate.

We assume that agents observe the level of labor productivity, but not its decomposition into the trend growth rate and level components. We further assume that agents know, that is, have estimated on past data, the signal-to-noise ratio $\phi \equiv \sigma_{\nu}^{2} / \sigma_{\epsilon}^{2}$. Given a new observation of $p_{t}$, the prior estimate of the trend growth rate $\hat{g}_{p, t-1}$ is updated by applying the steady-state Kalman filter:

$$
\hat{g}_{p, t}=\hat{g}_{p, t-1}+\lambda\left(\Delta p_{t}-\hat{g}_{p, t-1}\right),
$$

where $\lambda$, the steady-state gain, is given by

$$
\lambda=\frac{\phi}{2}(-1+\sqrt{1+4 / \phi})
$$

for $\phi>0$. This filter is optimal under the assumptions of the model (see Harvey 1989 for a full treatment).

\footnotetext{
${ }^{8}$ We also analyzed a version of this model that included variables related to the cyclical state of the economy that exert a transitory influence on measured productivity growth, such as cyclical utilization of factor inputs and adjustment costs, as in Nadiri and Rosen (1969). The results were very similar to those from the simple model described above.
} 
The key parameter for the Kalman filter is the gain $\lambda$ that translates surprise movements in the level of technology into perceived movements in the trend growth rate. Stock and Watson (1998) estimate a quarterly model of GDP growth similar to that described above with data through 1995, and their estimate implies a value of $\lambda$ of 0.03 (per quarter). Estimates by Roberts (2001) and Laubach and Williams (2003) that are based on data through the end of the 1990s imply somewhat higher values for the gain. ${ }^{9}$ In each case, the confidence bands around these estimates of the gain are very wide; for example, Laubach and Williams (2003) find that the 90 percent confidence interval for their estimate of $\lambda$ includes zero.

Based on the Stock and Watson (1998) estimate, for our model of annual data, we take 0.115 as our benchmark value of $\lambda$. Given the uncertainty regarding estimates of $\lambda$, we also consider two alternative values of $\lambda$ : a lower value of 0.08 and a higher value of 0.22 , where the latter is equal to the value reported by Roberts (2001).

\subsection{Real-time Kalman Filter Estimates}

To compute real-time Kalman filter estimates, we first construct a set of real-time historical annual data series of labor productivity, where each vintage of data corresponds to the data available to economists at the end of January, about the time when estimates from the $\mathrm{CBO}, \mathrm{CEA}$, and the SPF are reported. Throughout, the data source for a vintage is the $E R P$, which is published near the beginning of the year. ${ }^{10}$

As we show in detail below, the use of real-time data is crucial for understanding the evolution of historical long-run forecasts of productivity growth, especially during the late

\footnotetext{
${ }^{9}$ Note that all of these estimates are based on final, revised data, and therefore they ignore real-time measurement error noise that should damp the response of estimates of trend growth to unrevised data on productivity. As a result, these estimates of the gain are likely biased upwards relative to the optimal gain. The Kalman filter can be extended to include measurement error, which would yield a more complicated updating rule. We leave that for future research.

${ }^{10}$ Fourth-quarter data for the preceding year is not yet published in early January. Therefore, we construct a proxy for the fourth-quarter rate of productivity growth equal to the rate of productivity growth over the preceding three quarters. We then compute the annual growth rate using the published data for the first three quarters and our proxy for fourth-quarter growth. As a check on our method, we constructed alternative estimates using the real-time estimate of fourth-quarter productivity from the January or February Greenbook prepared by the staff of the Board of Governors for years that data is publicly available (through 1999). The resulting Kalman filter estimates were nearly identical to those reported in the paper.
} 
Table 3: Real-time Productivity Growth Data

\begin{tabular}{|c|c|c|c|c|c|c|c|c|c|c|}
\hline \multirow[b]{2}{*}{ Year } & \multicolumn{10}{|c|}{ Data Vintage (January) } \\
\hline & 1995 & 1996 & 1997 & 1998 & 1999 & 2000 & 2001 & 2002 & 2003 & 2004 \\
\hline 1990 & 0.5 & 0.5 & 0.5 & 0.5 & 0.5 & 1.2 & 1.2 & 1.2 & 1.2 & 1.3 \\
\hline 1991 & 1.5 & 0.6 & 0.7 & 0.7 & 0.7 & 1.6 & 1.2 & 1.2 & 1.2 & 1.3 \\
\hline 1992 & 2.7 & 3.2 & 3.2 & 3.2 & 3.1 & 4.1 & 3.7 & 3.7 & 3.7 & 3.6 \\
\hline 1993 & 1.5 & 0.2 & 0.2 & 0.1 & 0.1 & 0.1 & 0.5 & 0.5 & 0.5 & 0.5 \\
\hline 1994 & 2.2 & 0.5 & 0.5 & 0.4 & 0.5 & 1.3 & 1.3 & 1.3 & 1.3 & 1.3 \\
\hline 1995 & & 1.1 & 0.2 & 0.2 & 0.6 & 1.0 & 1.0 & 1.0 & 1.0 & 0.6 \\
\hline 1996 & & & 0.7 & 1.3 & 2.5 & 2.7 & 2.5 & 2.5 & 2.5 & 2.5 \\
\hline 1997 & & & & 1.9 & 1.4 & 1.9 & 1.8 & 2.0 & 2.0 & 1.6 \\
\hline 1998 & & & & & 2.1 & 2.8 & 2.7 & 2.6 & 2.6 & 2.6 \\
\hline 1999 & & & & & & 2.8 & 2.9 & 2.4 & 2.4 & 2.7 \\
\hline 2000 & & & & & & & 4.4 & 3.3 & 2.9 & 2.8 \\
\hline 2001 & & & & & & & & 1.7 & 1.1 & 2.2 \\
\hline 2002 & & & & & & & & & 4.9 & 4.8 \\
\hline 2003 & & & & & & & & & & 4.2 \\
\hline
\end{tabular}

1990s when data revisions were substantial. ${ }^{11}$ Table 3 reports the published rates of growth of labor productivity in the nonfarm business sector for each vintage of data from 1995 through 2004 (as described above). Published figures for productivity growth, especially for 1995 and 1996, changed dramatically as the data were revised. According to the 1997 vintage, productivity growth actually slowed in 1995 and 1996 relative to its average over the previous 20 years. The 1999 vintage exhibits upward revisions to productivity growth for 1995 and 1996, along with a strong figure for 1998. A portion of the upward revision in the 2000 vintage of productivity data reflects changes in the way that gross domestic output is measured in the national income accounts. According to analysis in the 2000 $E R P$, methodological changes boosted measured real GDP growth by 0.4 percentage point in 1987-1994, and by 0.2 percentage point in 1995-1998.

We next compute annual real-time Kalman filter estimates of trend productivity growth using our real-time data sets and the estimated value of the Kalman gain. For each vintage

\footnotetext{
${ }^{11}$ Gordon (2000) also emphasizes the importance of data revisions and changes in methodology in accounting for revisions to his estimates of trend productivity growth.
} 
Table 4: Kalman Filter Estimates of Long-Run Productivity Growth, 1995-2004

\begin{tabular}{ccccccccccccc}
\hline & Gain & \multicolumn{10}{c}{ Year } \\
\cline { 3 - 10 } & $\lambda$ & 1995 & 1996 & 1997 & 1998 & 1999 & 2000 & 2001 & 2002 & 2003 & 2004 \\
\hline Real-time data & & & & & & & & & & & \\
Benchmark & 0.115 & 1.3 & 1.2 & 1.0 & 1.2 & 1.4 & 1.9 & 2.2 & 2.0 & 2.2 & 2.6 \\
Low gain & 0.078 & 1.4 & 1.3 & 1.2 & 1.3 & 1.4 & 1.9 & 2.1 & 1.9 & 2.1 & 2.4 \\
High gain & 0.219 & 1.5 & 1.0 & 0.8 & 1.1 & 1.4 & 2.1 & 2.6 & 2.2 & 2.6 & 3.2 \\
Change from 1995 & & & & & & & & & & & \\
Benchmark & 0.115 & - & -.2 & -.3 & -.2 & .0 & .6 & .8 & .6 & .9 & 1.3 \\
Low gain & 0.078 & - & .0 & -.2 & -.1 & .1 & .5 & .7 & .5 & .7 & 1.0 \\
High gain & 0.219 & - & -.5 & -.5 & -.4 & .0 & .7 & 1.1 & .7 & 1.1 & 1.7 \\
Revised data & & & & & & & & & & & \\
Benchmark & 0.115 & 1.7 & 1.5 & 1.7 & 1.7 & 1.8 & 1.9 & 2.0 & 2.0 & 2.3 & 2.5 \\
Low gain & 0.078 & 1.8 & 1.7 & 1.7 & 1.7 & 1.8 & 1.9 & 1.9 & 2.0 & 2.2 & 2.3 \\
High gain & 0.219 & 1.6 & 1.4 & 1.6 & 1.6 & 1.8 & 2.0 & 2.2 & 2.2 & 2.8 & 3.1 \\
Change from 1995 & & & & & & & & & & & \\
Benchmark & 0.115 & - & -.1 & .0 & .0 & .1 & .2 & .3 & .3 & .7 & .9 \\
\multicolumn{2}{l}{ Low gain } & 0.078 & - & -.1 & .0 & .0 & .0 & .1 & .2 & .2 & .4 & .6 \\
High gain & 0.219 & - & -.2 & .0 & .0 & .3 & .5 & .6 & .6 & 1.2 & 1.5 \\
\hline
\end{tabular}

Notes: Real-time data simulations use data vintage available in January of indicated year.

Revised data simulations use data vintage available as of February 2004.

of productivity data, we start with an initial estimate of trend productivity growth and apply equation (3) to generate a time series of trend productivity estimates. The estimate for the last year of the time series - which is for the year before the vintage year - is our Kalman filter real-time estimate of labor productivity for the vintage year. ${ }^{12}$ The resulting

\footnotetext{
${ }^{12}$ Because we have historical data on productivity going back several decades, the estimates of trend growth at the end of the sample in any vintage are relatively insensitive to the assumed initial value of our state variable, trend productivity growth. For vintages through 1991, we have real-time productivity data back to 1947. For these vintages, we set the 1948 initial value of trend productivity growth at 3 percent, consistent with the average rate of productivity growth in the first 10 years of the sample. For vintages after 1991, we generally have only real-time productivity data back to 1959, and we set the 1959 estimate of trend productivity to 2.6 percent, consistent with the value implied by the benchmark Kalman filter estimate from the 1991 vintage. For the current vintage, we have data back to 1947.
} 
Figure 2: Evolution of Long-run Productivity Forecasts, 1996-2004

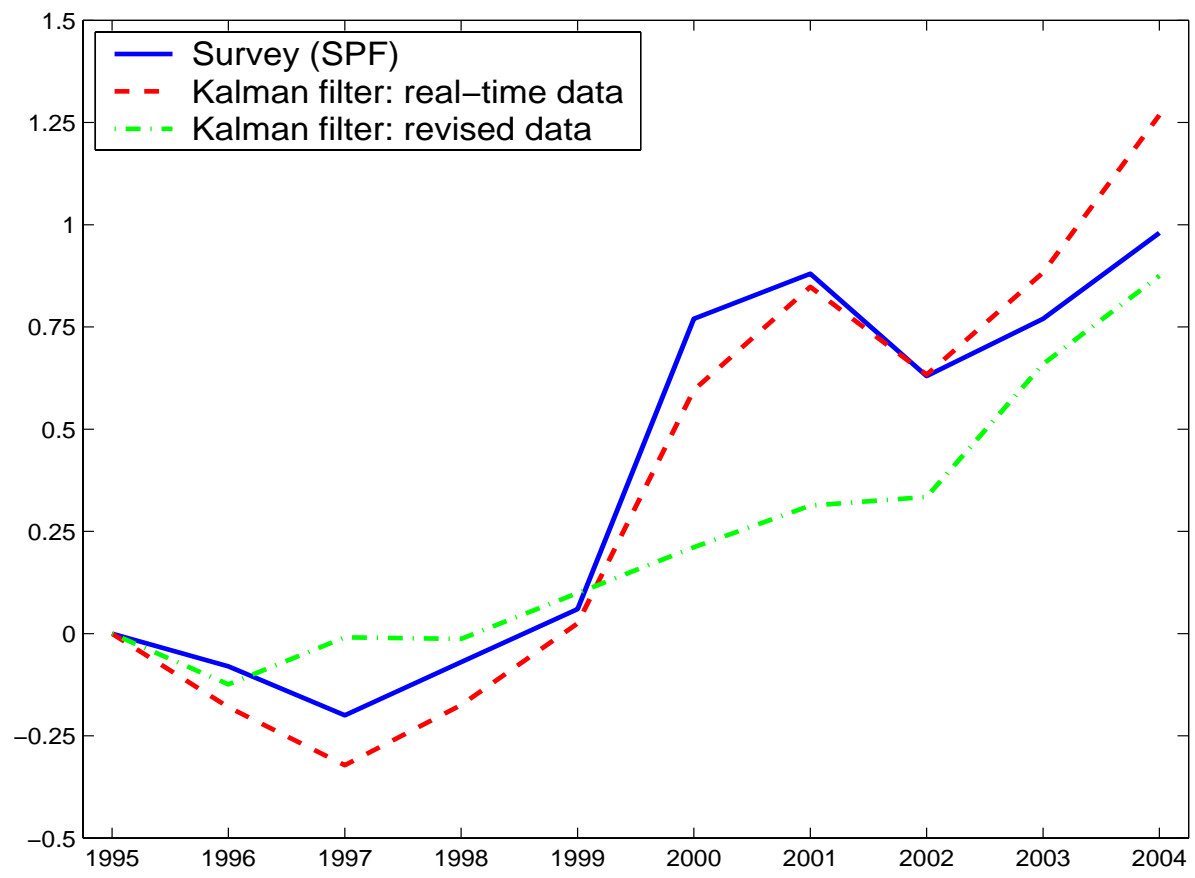

Notes: Each series is measured relative to its 1995 value. In each case, the Kalman gain is the benchmark value of 0.115 .

time series is reported in the Appendix. The estimates for vintages 1995 through 2004, implied by a gain $\lambda$ of 0.115 , are reported in the first row of Table 4 . The second row shows the estimates using the lower gain and the third row shows those from using the higher value of the gain. The fourth through sixth rows show the changes in the Kalman filter estimates from their respective 1995 values. (We return to the lower part of the table below.)

The year-to-year movements in the benchmark real-time Kalman filter estimates of trend productivity growth track those in the published estimates closely. The solid line in Figure 2 shows the changes in the mean estimates from the SPF plotted as deviations from its 1995 value. ${ }^{13}$ A striking feature of the Kalman filter estimates is that they not only follow the overall pattern of the SPF estimates, but they also follow all three turning points in the survey series (including the dips in 1997 and 2002 and the upturns in 1998, 2003, and

\footnotetext{
${ }^{13}$ As noted above, the levels of the series may differ owing to different measures of productivity. We are primarily interested in how such measures vary over time, and the normalization to a base year facilitates such comparisons.
} 
2004). Although not shown in the figure, the Kalman filter estimates also track well the estimates from the $\mathrm{CBO}$ and the CEA reported in Table 1. In addition, the benchmark Kalman filter estimates line up well with the real-time estimates reported by Blinder (1997) and Gordon $(1999,2000,2003)$ in the introduction of the paper. Note that since only past data on productivity growth are used in constructing the Kalman filter estimates, the close correspondence between these estimates and the published real-time estimates cannot be attributed to some auxiliary assumptions or data.

The Kalman filter estimates that use the higher value of the gain are more volatile than those in the SPF and those from the CBO, and the CEA. As seen in Table 4, the Kalman filter estimate using the high value of the gain is 1.7 percentage points above its 1995 level in 2004, while the published estimates rose only about 1 percentage point over the same period. The Kalman filter estimates based on a lower value of the gain of 0.078 , also reported in Table 4, are smoother than the benchmark estimate, and track the changes in the SPF over the 1996-2004 period about as well as the benchmark Kalman filter estimates. Indeed, a value of $\lambda$ of about of 0.10 yields Kalman filter estimates that best fit the changes in the SPF over this sample.

The close fit of the Kalman filter estimates of trend productivity growth to the published estimates in the recent episode depends critically on the use of real-time data. The lower portion of Table 4 reports Kalman filter estimates using revised data from February 2004. Unlike the real-time published estimates, the Kalman filter estimates using revised data show a steady rise during the second half of the 1990s, reflecting the rapid pace of productivity gains during that period. Comparing the two Kalman filter estimates in Figure 2 illustrates the critical importance of using real-time data in empirically analyzing the evolution of expectations.

Economists did not substantially revise upwards their views on trend growth earlier because the real-time productivity data through 1998 showed no evidence of any acceleration. As shown in Table 3, according to the data available in early 1997, productivity growth had actually slowed relative to its previous trend. This dip in productivity growth explains the drop in the real-time Kalman filter estimates and is consistent with the fall in the CBO and SPF estimates that year.

Upward revisions to past data and the robust pace of productivity growth in 1998 drive up the Kalman filter estimate in 1999, again consistent with the pattern seen in 
Table 5: Kalman Filter Estimates of Long-Run Productivity Growth, 1970-1980

\begin{tabular}{cccccccccccccc}
\hline & Gain & \multicolumn{10}{c}{ Vintage of Estimate (January) } \\
\cline { 3 - 11 } & $\lambda$ & 1970 & 1971 & 1972 & 1973 & 1974 & 1975 & 1976 & 1977 & 1978 & 1979 & 1980 \\
\hline Real-time data & & & & & & & & & & & & \\
Benchmark & 0.115 & 2.6 & 2.3 & 2.4 & 2.7 & 2.7 & 1.9 & 1.7 & 2.0 & 2.0 & 1.7 & 1.4 \\
Low gain & 0.078 & 2.7 & 2.5 & 2.6 & 2.7 & 2.7 & 2.2 & 2.0 & 2.2 & 2.1 & 1.9 & 1.7 \\
High gain & 0.219 & 2.4 & 1.9 & 2.2 & 2.8 & 2.8 & 1.3 & 1.2 & 1.9 & 1.9 & 1.4 & .9 \\
Change from & 1970 & & & & & & & & & & & \\
Benchmark & 0.115 & - & -.3 & -.2 & .1 & .1 & -.7 & -.9 & -.6 & -.6 & -.9 & -1.2 \\
Low gain & 0.078 & - & -.2 & -.1 & .0 & .0 & -.5 & -.7 & -.5 & -.6 & -.8 & -1.0 \\
High gain & 0.219 & - & -.5 & -.2 & .4 & .4 & -1.1 & -1.2 & -.5 & -.5 & -1.0 & -1.5 \\
Revised data & & & & & & & & & & & & \\
Benchmark & 0.115 & 2.6 & 2.4 & 2.6 & 2.7 & 2.8 & 2.3 & 2.3 & 2.5 & 2.4 & 2.2 & 1.9 \\
Low gain & 0.078 & 2.6 & 2.5 & 2.6 & 2.7 & 2.7 & 2.4 & 2.4 & 2.5 & 2.4 & 2.3 & 2.1 \\
High gain & 0.219 & 2.3 & 2.2 & 2.6 & 2.8 & 2.8 & 1.9 & 2.1 & 2.4 & 2.2 & 2.0 & 1.5 \\
Change from & 1970 & & & & & & & & & & & \\
Benchmark & 0.115 & - & -.1 & .1 & .2 & .2 & -.3 & -.2 & -.1 & -.2 & -.3 & -.6 \\
Low gain & 0.078 & - & -.1 & .0 & .1 & .1 & -.2 & -.2 & -.1 & -.2 & -.3 & -.5 \\
High gain & 0.219 & - & -.2 & .2 & .4 & .5 & -.5 & -.3 & .0 & -.2 & -.3 & -.9 \\
\hline \hline
\end{tabular}

the contemporaneous published sources. Then, the comprehensive revision of the national accounts in late 1999 had a dramatic effect on the Kalman filter estimates and heavily influenced economists' views of trend productivity growth, as evidenced by the large upward revision in the estimates published in early 2000. As noted above, methodological changes in the national income accounts that took effect in late 1999 boosted estimates of past output growth, and the effects of these changes and the revisions to recent data are reflected in the 2000 vintage Kalman filter estimates. ${ }^{14}$ This pattern of relatively weak real-time estimates of long-run productivity growth, followed by a significant upward revision, accounts for the wide divergence in the Kalman filter estimates between those based on real-time data and

\footnotetext{
${ }^{14}$ Forecasters were aware of these methodological issues at the time. In fact, the SPF asked a special question in the fall of 1999 regarding the effects of the benchmark revision on respondents estimates of long-run growth, and the mean upward revision was about 0.2 percentage point.
} 
Figure 3: Evolution of Long-run Productivity Expectations in the 1970s

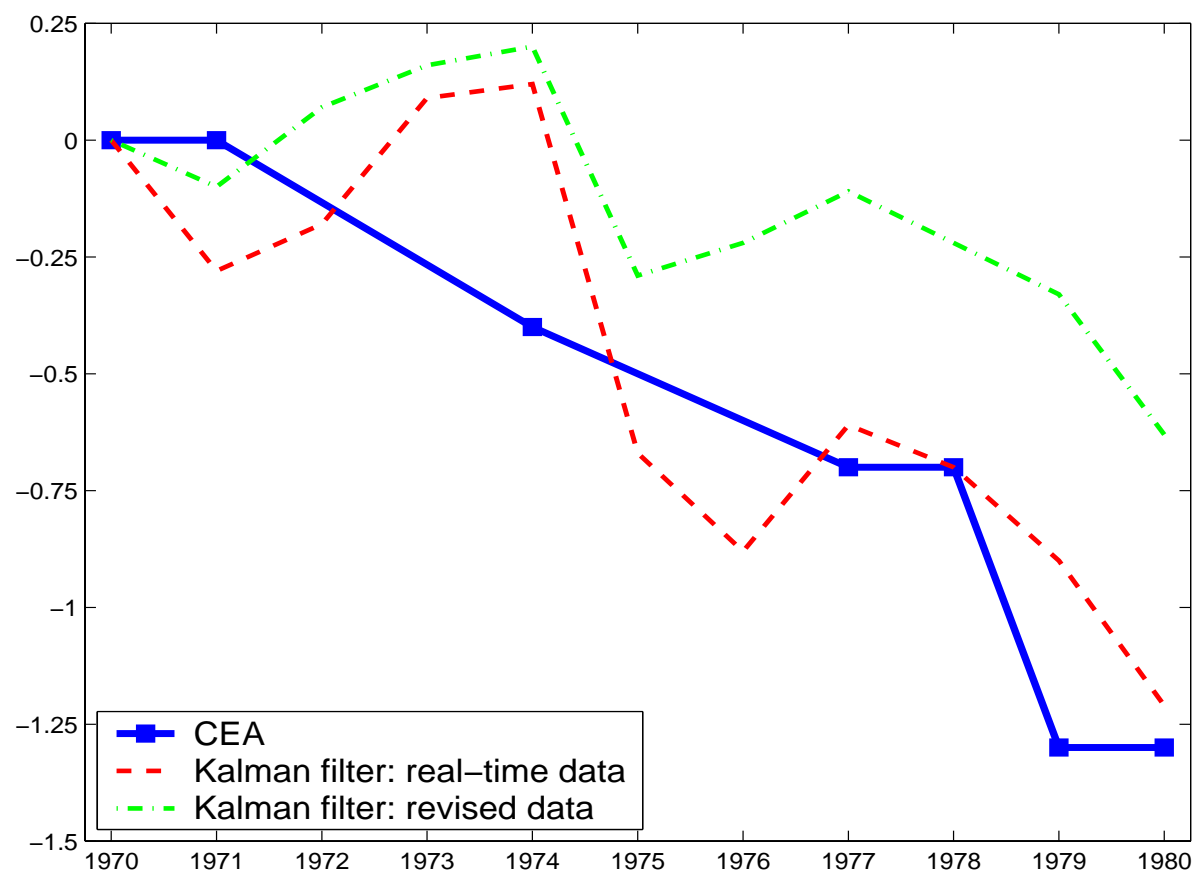

Notes: All series are relative to the respective 1970 value. The squares indicate the available observations. The Kalman filter estimates are based on an annual gain of 0.115.

those based on revised data.

Kalman filter estimates from the 1970s track the implicit estimates of trend productivity growth from the CEA during the late 1970s reasonably well. The solid line in Figure 3 shows the CEA estimates (the squares indicate years for which we have readings from the $E R P$ ). The dashed line shows the benchmark Kalman filter estimates. The estimates for the three values of the gain are reported in the upper part of Table 5. As before, the Kalman filter estimates with the high value of the gain are excessively volatile relative to the real-time published estimates.

Overall, the benchmark Kalman filter estimates do a remarkable job of matching the real-time estimates of long-run productivity growth during the periods of the productivity slowdown in the 1970s and following the acceleration in the 1990s. We now turn to the implications of gradual recognition on the dynamic responses of the economy to a shift in the trend rate of productivity growth. 


\section{The Model Economy}

We illustrate the effects of the gradual recognition of a shift in productivity growth using a standard two-sector neoclassical growth model with endogenous labor supply. In this section, we describe a standard real business cycle model and the solution method. In the following section, we analyze the effects of permanent shocks to the growth rate of productivity.

\subsection{Production Technology and Preferences}

Let $C_{t}$ and $I_{t}$ denote the output of the consumption and investment goods sectors in period $t$. The technologies to produce consumption and investment are assumed to be identical except for a scale factor reflecting the different levels of TFP in the two sectors. Specifically, the production of consumption and investment goods are given by:

$$
\begin{aligned}
C_{t} & =A_{t}^{1-\alpha} K_{c, t}^{\alpha} L_{c, t}^{1-\alpha} \\
I_{t} & =\left(Z_{t} A_{t}\right)^{1-\alpha} K_{i, t}^{\alpha} L_{i, t}^{1-\alpha}
\end{aligned}
$$

where $K_{j, t}$ and $L_{j, t}$ denote the quantities of capital and labor employed in each sector $j, A_{t}$ represents the aggregate technology process that affects both sectors equally, and $Z_{t}$ is the technology process that is specific to the investment-goods producing sector.

The aggregate capital accumulation technology is given by:

$$
K_{t+1}=(1-\delta) K_{t}+I_{t}
$$

where $\delta$ is the rate of physical depreciation. We assume that capital is freely mobile across the two sectors, where the sum of the two capital stocks used in production is restricted not to exceed the aggregate capital stock; specifically, $K_{c, t}+K_{i, t} \leq K_{t}$.

The representative household's welfare at time 0 is given by:

$$
E_{0} \sum_{t=0}^{\infty} \beta^{t} U_{t},
$$

where $\beta$ is the household's rate of time preference and $U_{t}$ denotes the momentary utility in period $t$. Utility is given by:

$$
U_{t}= \begin{cases}\ln \frac{C_{t}}{H_{t}}+\zeta \ln \left(1-\frac{L_{t}}{H_{t}}\right) & \text { for } \gamma=1 \\ \frac{1}{1-\gamma}\left[\frac{C_{t}}{H_{t}}\left(1-\frac{L_{t}}{H_{t}}\right)^{\zeta}\right]^{1-\gamma} & \text { otherwise }\end{cases}
$$


where $H_{t}$ denotes the size of the household, $L_{t}$ represents total labor input from the household, $\gamma$ is the inverse of the household's intertemporal elasticity of consumption, and $\zeta$ is a parameter that governs the household's elasticity of labor supply. We assume that labor is freely mobile across the two sectors, where the sum of the labor inputs in the two sectors cannot exceed the aggregate labor input that period: $L_{c, t}+L_{i, t} \leq L_{t}$, which itself may not exceed the aggregate time endowment. Since we normalize the time endowment of each member of the household to unity, the aggregate time endowment is equal to $H_{t}$. We assume that the population grows at a constant gross rate $G_{h}$, specifically, $H_{t+1}=G_{h} H_{t}$.

\subsection{The Decentralized Competitive Equilibrium}

Given the assumptions regarding technology and preferences and the absence of distortions in the model economy, the decentralized competitive equilibrium is equivalent to the solution of the social planning problem that maximizes the welfare of the representative agent. We start by characterizing the solution to the social planner's problem with complete information about all shocks. In the next section, we turn to the solution where expectations are based on an estimate of long-run productivity growth computed using a version of the Kalman filter.

The planner's problem in period $t$ is to maximize household welfare (equation 8) subject to the consumption and investment sector production functions (equations 5 and 6), the accumulation equation (equation 7), and the two factor market constraints. The resulting first-order conditions to the social planner's problem are given by:

$$
\begin{aligned}
\frac{C_{t}}{K_{c, t}} & =\frac{I_{t} Z_{t}^{-(1-\alpha)}}{K_{i, t}}, \\
\frac{C_{t}}{L_{c, t}} & =\frac{I_{t} Z_{t}^{-(1-\alpha)}}{L_{i, t}} \\
U_{c, t}^{\prime} Z_{t}^{-(1-\alpha)} & =\beta E_{t} U_{c, t+1}^{\prime}\left(\alpha \frac{C_{t+1}}{K_{c, t+1}}+(1-\delta) Z_{t+1}^{-(1-\alpha)}\right), \\
\zeta \frac{L_{c, t}}{H_{t}} & =(1-\alpha)\left(1-\frac{L_{t}}{H_{t}}\right),
\end{aligned}
$$

where $U_{c, t}^{\prime}$ denotes the marginal utility of consumption. Equations (10) and (11) equate the marginal product of capital and labor across the two sectors. Because the production functions are identical up to a multiplicative term, the two sectors employ labor and capital in the same proportions in both sectors. Equation (12) is the standard intertemporal Euler 
equation, augmented to include changes in the relative productivity of the investment goods sector. Equation (13) is the within period condition for the choice of labor input. The marginal rate of transformation between investment goods and consumption, that is, the relative "price" of investment goods, is given by $Z_{t}^{-(1-\alpha)}$.

It is useful to construct a real output measure consistent with the current use of chainweighted aggregation in the U.S. national income accounts. Correspondingly, we define real aggregate output, $Y_{t}$, as the Divisia index sum of real consumption and real investment:

$$
\Delta \ln Y_{t}=\frac{C_{t}}{Y_{t}^{N}} \Delta \ln C_{t}+\frac{I_{t}^{N}}{Y_{t}^{N}} \Delta \ln I_{t}
$$

where $I_{t}^{N}\left(\equiv I_{t} Z_{t}^{-(1-\alpha)}\right)$ represents nominal investment and $Y_{t}^{N}\left(\equiv C_{t}+I_{t}^{N}\right)$ denotes nominal output. Again for comparison to the data, we construct a synthetic real 10-year bond rate, $R^{b}$, determined according to an approximation of the expectations theory of the term structure:

$$
R_{t}^{b}=\frac{1}{11}\left(R_{t}+E_{t} 10 R_{t+1}^{b}\right)
$$

where $R_{t}=Z_{t}^{(1-\alpha)} E_{t}\left(\alpha \frac{C_{t+1}}{K_{c, t+1}}+(1-\delta) Z_{t+1}^{-(1-\alpha)}\right)$ is the ex ante real return to capital.

\subsection{The Deterministic Steady State}

To characterize the deterministic balanced growth steady state of the model, we assume that $A$ and $Z$ increase at constant gross growth rates $G_{a}$ and $G_{z}$, respectively. The steady-state growth rates of consumption, investment, and output are then given by:

$$
\begin{aligned}
G_{c} & =G_{h} G_{a} G_{z}^{\alpha}, \\
G_{i} & =G_{h} G_{a} G_{z}, \\
G_{y} & =G_{c}^{s_{c}} G_{i}^{1-s_{c}}, .
\end{aligned}
$$

where $G_{x}$ denotes the steady-state gross growth rate of variable $X$, and $s_{c}$ denotes the steady-state ratio of labor employed producing consumption goods. Along the balanced growth path, labor input increases at a gross rate $G_{h}$, and the aggregate capital stock increases at the same rate as investment. In the steady-state, hours per person is constant. Thus, the steady-state rate of growth of labor productivity equals the ratio of the steadystate growth rate of output to that of population. Nominal investment and nominal output increase at the same rate as real consumption. 
To solve and simulate the model, it is useful to work with normalized variables, which are denoted by lower case letters. In particular, the following normalizations yield stationary variables along the balanced growth path: $l=\frac{L}{H}, c=\frac{C}{H A Z^{\alpha}}, i=\frac{I}{H A Z}, k=\frac{K}{H A Z}$.

The first-order condition for the consumption-saving choice (equation 12) yields the following steady-state relationship between the gross real rate of return on capital, $R$, and the growth rate of per capita consumption:

$$
R=\beta^{-1}\left(\frac{G_{c}}{G_{h}}\right)^{\gamma}
$$

The steady-state ratio of the normalized capital stock to normalized output, denoted by $\kappa$, is given by:

$$
\kappa=\frac{\alpha G_{z}^{-(1-\alpha)}}{R-(1-\delta) G_{z}^{-(1-\alpha)}}
$$

The steady-state share of labor used to produce consumption goods is given by:

$$
s_{c}=1-\left(G_{i}-1+\delta\right) \kappa .
$$

The labor-leisure choice yields the steady-state per capita labor supply, denoted by $l$,

$$
l=\frac{1-\alpha}{\zeta s_{c}+1-\alpha} .
$$

\subsection{Calibration}

For the simulations, we calibrate the model to annual data using standard parameter values taken from the literature. In particular, we set $\alpha=0.36, \beta=0.98, \gamma=1, \zeta=3$, and $\delta=0.10$. We calibrate the steady-state growth rates from long-run post-war averages: $G_{z}=$ $1.014, G_{a}=1.014$ and $G_{h}=1.014$. Together these imply annual steady-state per capita growth rates of 1.9 percent for consumption, 2.8 percent for investment, and 2.2 percent for chain-weighted output (and labor productivity).

\subsection{Solution Method}

The model simulations consider permanent shocks to the trend growth rates of technology. Unlike shocks to the level of technology typically studied in the literature, these shocks imply permanent changes in the levels of normalized variables. For example, the steadystate consumption share and labor input both depend on the steady-state growth rates $G_{a}$ and $G_{z}$. Therefore, log-linear approximations around a particular steady-state may provide 
relatively poor approximations to the dynamic response to growth shocks. For this reason, we use nonlinear methods to compute the dynamic responses to the shocks. Following Judd (1992), we use higher-order polynomial approximations to the decision rules describing the behavior of the economy. ${ }^{15}$

We use orthogonal collocation, which is an application of Galerkin methods described in Fletcher (1984), to compute the approximate decision rules. In particular, the decision rules for labor input and consumption are approximated by fifth-order polynomial functions of the three state variables: the normalized capital stock, the trend growth rate of aggregate technology, and the trend growth rate of investment-goods technology. A Chebyshev polynomial basis is used to represent the decision rules; tensor products of the states are used in the polynomial representations. A nonlinear equation solver is used to find the coefficients of the decision rules that satisfy the stochastic first-order equations at a fixed set of points in the three states, where the points are the roots of the Chebyshev polynomial basis. Expectations in the first-order equations are approximated using an eight-point Gauss-Hermite quadrature rule. This method is extremely efficient and accurate. ${ }^{16}$ Using these approximate decision rules and the law of motion of the economy, we compute impulse responses to shocks to the technology processes, with each impulse response starting at the balanced-growth steady state.

\section{Effects of Shifts in the Trend Growth Rate}

In this section, we consider simulations of permanent shocks to the growth rate of technology. We consider two alterative sources for the shift in productivity growth. In one, the change affects both the consumption and investment goods sectors equally, roughly consistent with the evidence from the productivity slowdown in the 1970s. In the second, the

\footnotetext{
${ }^{15}$ We compared the simulation results using the nonlinear method to those obtained using a loglinearization of the system. The log-linear simulations were generally reasonably close to those using the nonlinear method; the largest deviation occurs in the response of labor input.

${ }^{16}$ It takes 20 seconds on a $1.2 \mathrm{Mhz}$ Pentium III computer to solve for the fifth-order polynomial decision rules of this model. One metric for approximation error used by Judd (1992) is the maximum absolute error in the first-order equations, normalized to be in terms of consumption units, computed over a wide range of points for the state variables. For the model in this paper, the maximum absolute error is less than 0.001 percent.
} 
shift occurs only in the investment goods sector, consistent with the evidence of Cummins and Violante (2002) regarding the productivity acceleration in the 1990s. We first examine the long-run implications of such shocks and then analyze the dynamic path via which the model economy arrives at the new long-run equilibrium.

\subsection{Steady-state Effects}

Consider first the steady-state effects of a permanent increase in the growth rate of the aggregate technology process, $G_{a}$. From the steady-state conditions we see that a percentage point increase in the growth rate of aggregate technology implies an increase of the same magnitude in the steady-state growth rates of per capita consumption, investment, and output (equation 15 and 17). The implied faster rate of decline in marginal utility implies a higher real return on capital (equation 18), as consumers demand a higher return on savings to forgo consumption today. The higher real return in turn implies a lower steady-state normalized capital-to-output ratio (equation 19). The consumption-to-output ratio (equation 20) may rise or fall depending on two opposing effects: Faster growth necessitates greater investment to hold the normalized capital-to-output ratio constant; but, the higher rate of return implies a lower optimal capital-to-output ratio. It is not possible to sign a priori the net effect on the consumption-to-output ratio. In addition, it is not possible to sign the steady-state effect on labor supply (equation 21), since labor supply is a decreasing function of the consumption-to-output ratio. For our calibration, the former effect dominates, and the steady-state consumption-to-output ratio falls in response to an

increase in the rate of growth of aggregate TFP. As a result, labor supply rises slightly with an increase in $G_{a}$.

Now consider the effects of a permanent increase in the growth rate of the investmentspecific technology process $G_{z}$. A percentage point increase in the growth rate of investmentsector TFP has a smaller effect on consumption growth than a change in aggregate TFP growth of the same magnitude (equation 15), since the former increases consumption growth only through the capital-deepening channel. We therefore consider a slightly larger increase in the growth rate of $G_{z}$; specifically, one which yields a percentage point increase in the growth rate of consumption and hence an increase in the real interest rate equal to that implied by our aggregate TFP growth-rate shock (equation 18). Despite generating the same-sized increase in real interest rates, the investment sector productivity acceleration- 
Figure 4: Productivity Acceleration with Immediate Recognition
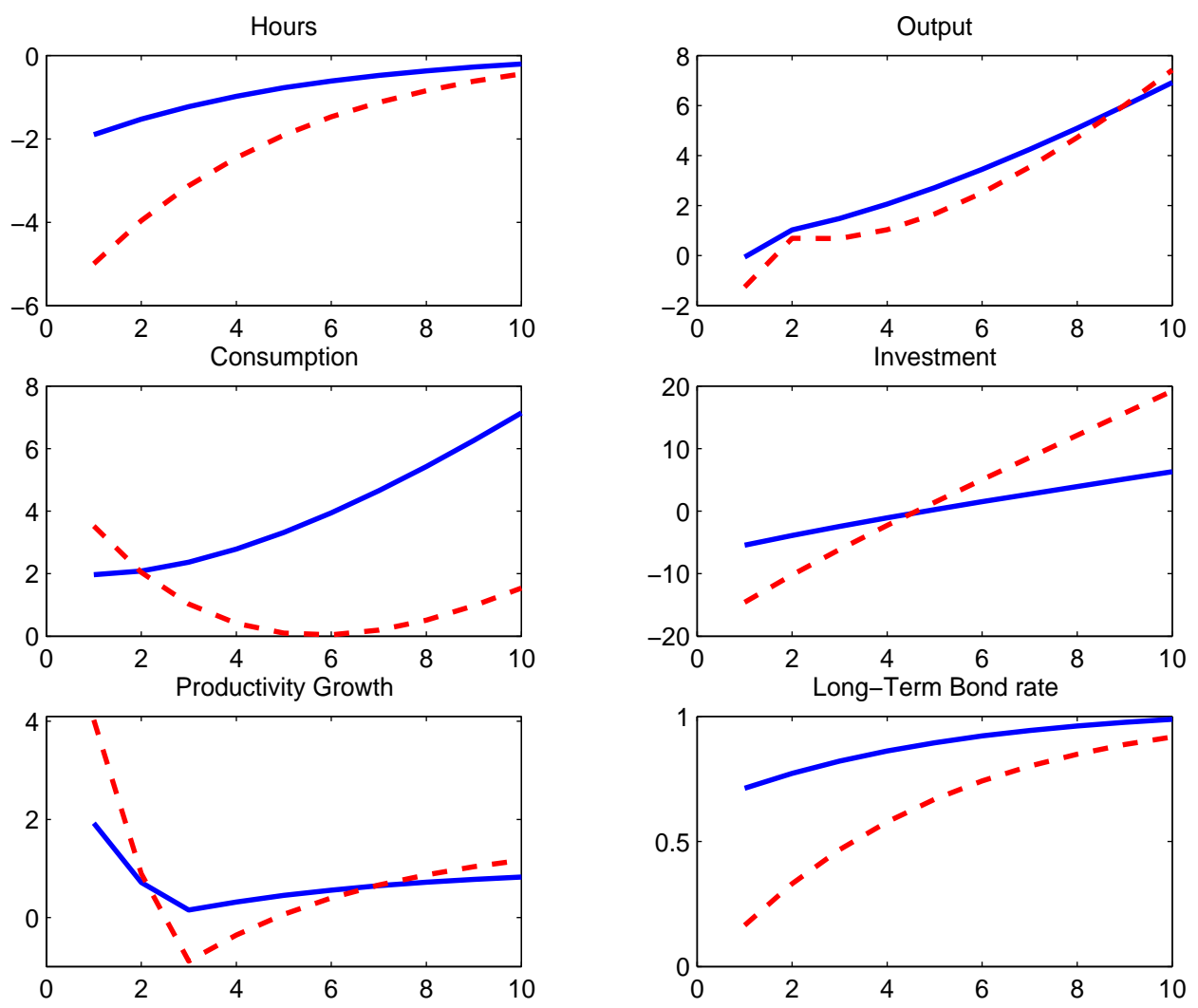

Notes: Productivity growth and the long-term bond rate are measured as percentage point deviations from their respective pre-shock steady state value; all other variables are shown as percent deviations from the pre-shock steady state. The horizontal axis is measured in years.

since it also implies a larger capital loss - results in a slightly greater increase in the cost of capital and hence a slightly larger decrease in the capital-to-output ratio (equation 19). As in the case of an acceleration in aggregate TFP, it is not possible to sign the effect of an acceleration in investment-goods TFP on the nominal consumption-to-output ratio or of the labor supply (equation 20 and 21). For our calibration, the nominal consumption-to-output ratio falls, implying that the labor supply increases with an increase in $G_{z}$. 


\subsection{Dynamic Responses to an Observed Productivity Acceleration}

We now consider the effects of an unanticipated increase in the rate of growth of aggregate TFP that is immediately observed, where the shock is scaled to yield a one percentage point long-run increase in the growth rates of consumption. The solid lines in Figure 4 show the results of this experiment.

At the onset of an increase in the rate of trend aggregate TFP growth, the existing capital-to-output ratio exceeds its new steady-state level, since, as just discussed, the higher rate of long-run growth implies a higher long-run rate of return, as seen by the response of the long-term bond rate. The equilibrium response to the resulting capital overhang is a sharp decline in investment, which generates the required liquidation of capital. Consumption increases immediately following the shock, offsetting the decline in investment and leaving output about unchanged, and hours decline. ${ }^{17}$ These negative responses of investment and hours following a positive shock to aggregate TFP growth are consistent with the "perverse" pattern noted by Campbell (1994). ${ }^{18}$ After the initial phase during which capital stocks are run down, investment growth picks up again and attains its new balanced growth path. In the long run, consumption, investment, and output increase one percentage point faster than before the shock to aggregate TFP growth.

Qualitatively, the responses to an unanticipated permanent increase in the growth rate of investment-specific TFP — shown by the dashed lines in Figure 4-are similar to those of an upward shift in the growth rate of economy-wide TFP. The shock is scaled to yield the same one percentage point increase in the growth rate of consumption and nominal output as the previous experiment. Real investment initially falls following the shock as do hours and real output.

\subsection{Dynamic Responses with Learning}

We now modify the model to allow for imperfect information about whether the shock to productivity growth is transitory or permanent. As noted in the introduction, we assume

\footnotetext{
${ }^{17}$ In this model, hours rise in response to a productivity acceleration only if labor supply is highly inelastic and households have a very high rate of intertemporal substitution.

${ }^{18}$ Campbell (1994) simulated a highly persistent negative shock to the rate of productivity growth, while we simulate a permanent positive one. The distinction between a highly persistent shock and a permanent one is not important, as the two experiments yield qualitatively similar results.
} 
Figure 5: Productivity Acceleration with Gradual Recognition
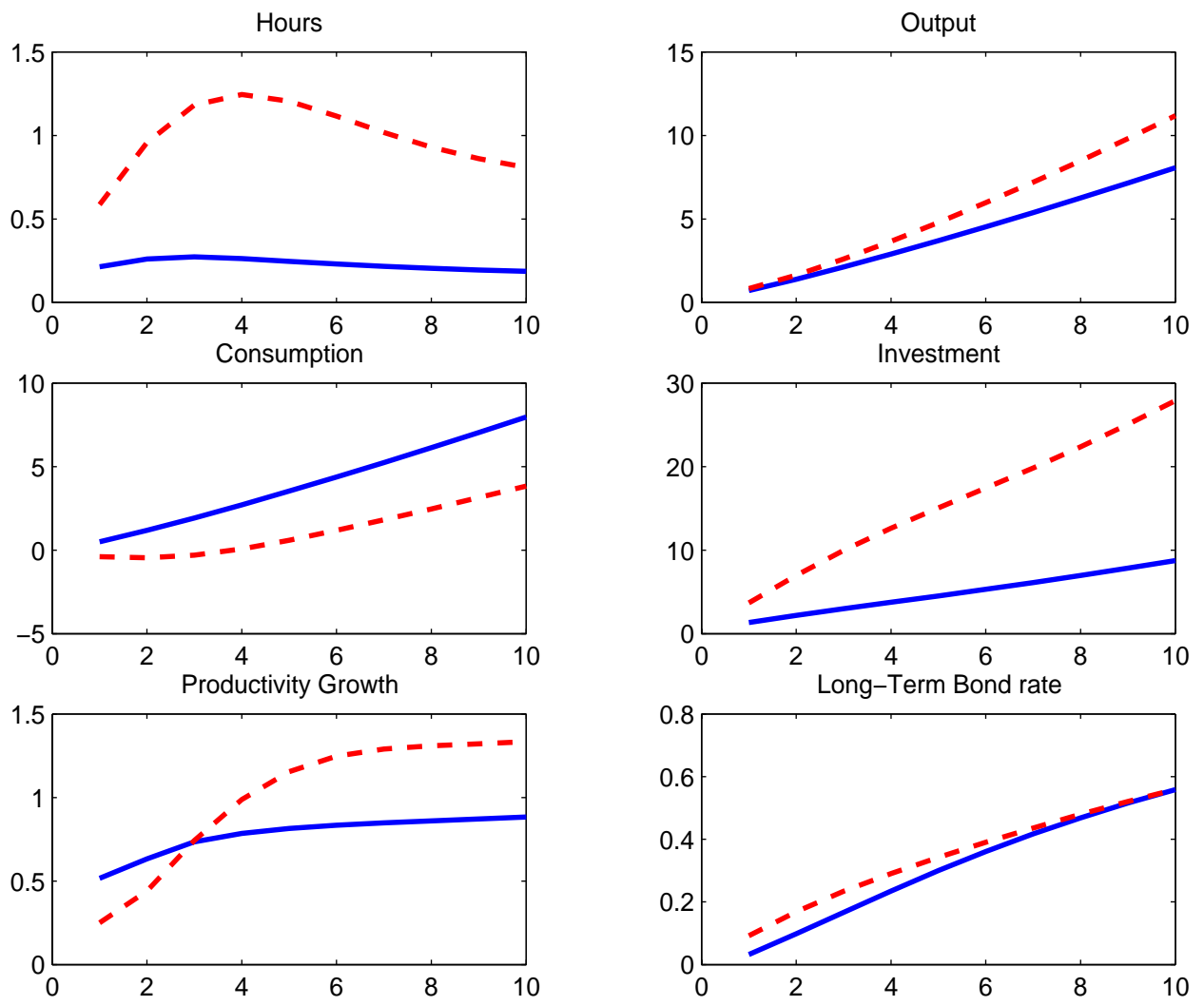

Note: See Figure 4.

that agents in the model economy face the same signal extraction problem in separating transitory from permanent movements in productivity growth as econometricians studying macroeconomic data. ${ }^{19}$ In particular, we assume that agents observe only the aggregate level of labor productivity and update their estimate of the long-run growth rate of productivity using the Kalman filter updating equation (equation 3). We assume that agents initially know the growth rate of aggregate technology, $G_{a}$, and of investment-sector technology, $G_{z}$, and in the simulation they increase their estimate of $G_{a}$ one-for-one with the increase

\footnotetext{
${ }^{19} \mathrm{An}$ interesting extension of our analysis would be the case where agents have asymmetric information about idiosyncratic shocks versus aggregate shocks, viewing a shift in productivity growth as primarily idiosyncratic to their own experience and update their views of aggregate productivity growth using the Kalman filter.
} 
in the estimate of trend labor productivity generated by Kalman filter updating. ${ }^{20}$ Note that for this experiment the updating of trend productivity growth is applied only to the perceived trend growth rate of aggregate TFP; we assume that the perceived trend growth rate of investment-specific TFP is not affected. We set the gain $\lambda$ for updating estimates of trend labor productivity growth equal to 0.115 , consistent with the evidence from Kalman filter estimation and from economists' real-time estimates of trend productivity growth, as discussed above. (Later, we examine the sensitivity of our results to the choice of the gain.)

In an economy where agents filter incoming information to estimate the trend productivity growth rate, hours, output, and investment all rise in response to a permanent increase in aggregate TFP growth, and, as a result, the economy experiences a prolonged boom. The solid line in Figure 5 reports the results from the same experiment of a permanent increase in the growth rate of aggregate TFP as before but with gradual recognition of the source of the shock. In the first few years after the onset of the shock, agents believe that the trend growth rate has risen only very modestly and attribute most of the higher level of productivity to a sequence of positive shocks to the level of productivity $\left(\epsilon_{t}\right.$ shocks in terms of our notation in equations 1 and 2). In this model, such level shocks boost hours, output, and investment, with only relatively small effects on the real interest rate. ${ }^{21}$ Only when the perceived long-run rate of productivity growth rises do rates on long-term bonds rise significantly as well. ${ }^{22}$

\footnotetext{
${ }^{20}$ We also have conducted these experiments assuming that agents directly update their expectations of trend TFP growth based on observations of TFP instead of indirectly through their observations of labor productivity growth. The results are very similar to those reported here.

${ }^{21}$ Our model predicts hours to increase following a positive permanent shock to the level of technology and is in this respect consistent with the empirical responses reported by Altig, Christiano, Eichenbaum, and Linde (2002) and Christiano, Eichenbaum, and Vigfusson (2003a, 2003b). In contrast, Basu, Fernald, and Kimball (1998), Galí (1999), and Francis and Ramey (2001) find that hours initially decline in response to a positive permanent shock to the level of TFP, although this decline is generally only transitory such that a rise in employment eventually transpires. Thus, even in a model that generates an hours response similar to the those found by these authors, a string of positive shocks still leads to a lagged boom in employment. Thus, our conclusions as to the importance of agents initially mistaking an acceleration in TFP growth as a sequence of TFP level shocks do not rely on sign of the impact response of hours to a permanent shock to the level of productivity.

${ }^{22}$ Brayton and Reifschneider (2001) examine shifts in long-run productivity using the Federal Reserve's large-scale macroeconomic model, and also find that an increase in the long-run rate of productivity growth generates a sustained boom in employment and investment. Importantly, in their model simulations, interest
} 
The effects of an acceleration in productivity in the investment-goods sector alone is shown by the dashed lines of Figure 5. For this experiment, we assume that agents understand that the shock is specific to the investment-goods sector but do not know whether the increase in productivity growth is transitory or permanent. We use the same gain $\lambda$ as before but adjust the updating formula to reflect the fact that an increase in $G_{z}$ has a proportionally smaller effect on aggregate labor productivity growth than a similar-sized increase in $G_{a}$. In the calibrated model, $G_{z}$ must increase by 0.018 to raise the steady-state growth of output by 0.01 . Thus, we multiply an increase in estimated trend aggregate labor productivity growth by a factor of 1.8 to compute the implied increase in the perceived value of $G_{z}$.

As before, the productivity acceleration generates a prolonged rise in hours and a monotonic increase in the rate of labor productivity growth and the long-term bond rate. One interesting distinction between the two shocks is that the dynamics of the investment-goods sector productivity acceleration are more drawn out.

Learning has important implications for the response of long-term bond rates to shifts in trend productivity. If an increase in the long-run rate of productivity growth were immediately recognized, the model predicts a significant rise in real long-term yields within a few years of the onset of the shock. With learning, real-long terms yields rise very gradually during the decade following the shock. The evidence from SPF expectations of future real interest rates during the late 1990s provides some support for the model with learning. SPF long-run expectations of real interest rates changed relatively little during the late 1990s, before declining during the recession of 2001. Similarly, yields on inflationindexed securities (TIIS) increased gradually during the late 1990s. ${ }^{23}$ Of course, other factors, including fiscal policy and the state of the business cycle, influenced expectations of real interest rates during this period, making a sharp comparison of the model predictions and the data difficult.

In summary, the model with learning predicts that a productivity acceleration leads to a prolonged boom in hours and a steady increase in the rate of output and productivity growth. The implied rise in long-term real rates occurs very gradually. These results are

rates rise only gradually in response to the faster rate of growth.

${ }^{23}$ TIIS securities were first issued in early 1997. See Bomfim (2001) for a discussion of the use of TIIS yields in measuring real rate expectations. 
Figure 6: Sensitivity to Gain: Aggregate TFP Acceleration
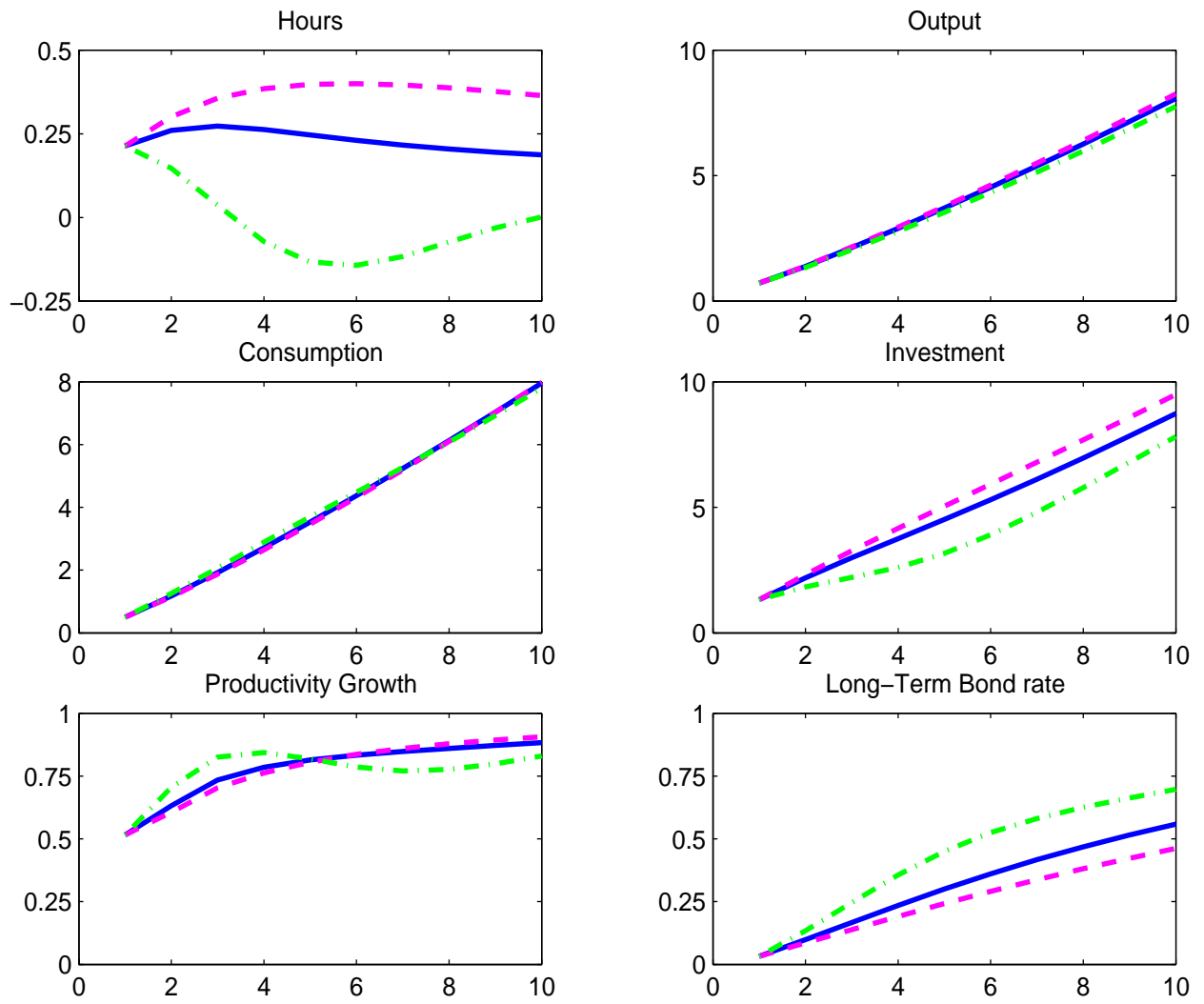

Note: See Figure 4.

robust to reasonable variations in the assumed gain parameter. Figures 6 and 7 show dynamic responses for the benchmark calibration (the solid line), a lower gain of 0.08 (the dotted line), and a higher gain of 0.22 (the dashed-dotted line) to a permanent increase in the growth rate of aggregate TFP and to investment-goods sector TFP, respectively. In all cases, the productivity acceleration produces a sustained boom in investment and output and a gradual rise in the long-term real interest rate.

\section{Conclusion}

This paper documents the difficulty of estimating long-run productivity growth in real time and establishes the importance of learning for understanding the macroeconomic consequences of shifts in the trend productivity growth rate. We find that a simple linear updating rule based on an estimated Kalman filter model provides an extremely good de- 
Figure 7: Sensitivity to Gain: Investment-Goods Sector TFP Acceleration
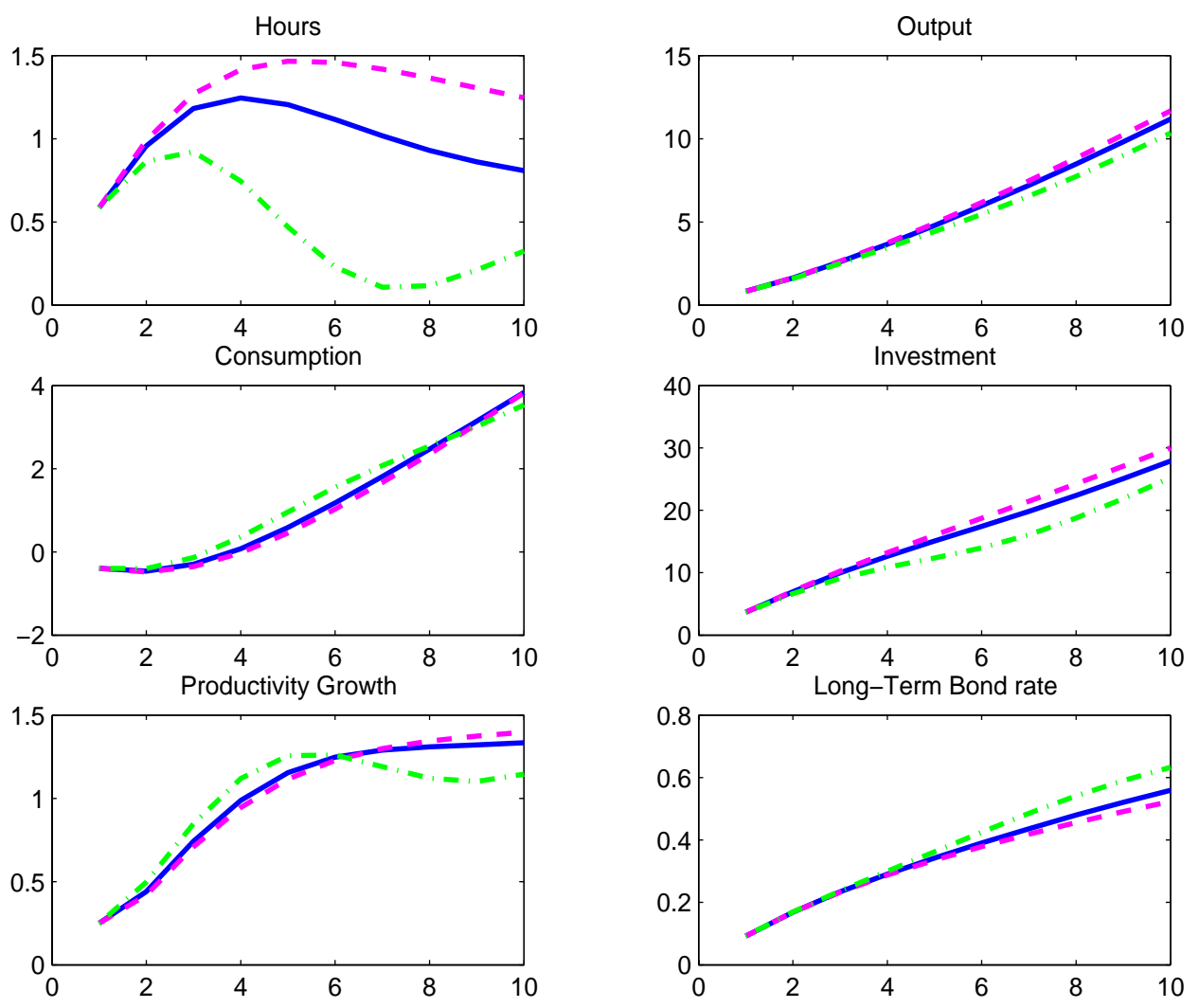

Note: See Figure 4.

scription of the evolution of economists' real-time estimates of long-run productivity growth over both the 1970s and 1990s. We then show that incorporating the gradual recognition of shifts in trend growth rate has considerable implications for the dynamic responses to such shocks: If immediately recognized, an increase in the long-run productivity growth rate - in what is markedly at odds with historical experience - causes long-term interest rates to rise and generates a sharp decline in employment and investment. By contrast, an identical model that differs only in that it allows for the gradual recognition of shifts in the trend growth rate of TFP can, following a sustained rise in the rate of productivity growth, generate positive and prolonged responses for hours and investment, and a more gradual increase in long-term interest rates. Moreover, for our preferred calibration of the pace of learning about productivity growth rate shifts - which equals the learning rate consistent with published real time estimates of long-run productivity growth-an increase (decrease) 
in the long-run growth rate of productivity generates a sustained employment and investment boom (slump). This prediction represents a dramatic improvement in our model's ability to generate responses to long-run productivity growth rate shifts that resemble the experiences of the 1970s and 1990s.

\section{References}

[1] Altig, David, Lawrence J. Christiano, Martin Eichenbaum, and Jesper Linde. "Technology Shocks and Aggregate Fluctuations." Federal Reserve Bank of Chicago, manuscript, June 2002.

[2] Andrews, Donald, Inpyo Lee, and Werner Ploberger. "Optimal Changepoint Tests for Normal Linear Regression." Journal of Econometrics 70(1), January 1996, 9-38.

[3] Ball, Laurence and Robert Moffitt. "Productivity Growth and the Phillips Curve." Johns Hopkins University, manuscript, June 2001.

[4] Basu, Susanto, John Fernald, and Miles S. Kimball. "Are Technology Improvements Contractionary?" Federal Reserve Board, International Finance Discussion Papers 625, September 1998.

[5] Basu, Susanto, John Fernald, and Matthew D. Shapiro. "Productivity Growth in the 1990s: Technology, Utilization, or Adjustment?" Federal Reserve Bank of Chicago Working Paper 2001-4, June 2001.

[6] Blinder, Alan S. "The Speed Limit: Fact and Fancy in the Growth Debate." The American Prospect 8(34) September-October 1997.

[7] Blinder, Alan S., and Janet L. Yellen. "The Fabulous Decade: Macreconomic Lessons from the 1990s." In: Alan B. Krueger and Robert M. Solow (eds.) The Roaring 1990s: Can Full Employment Be Sustained? New York: Russel Sage Foundation, 2002.

[8] Bomfim, Antulio N. "Measuring Equilibrium Real Interest Rates: What Can We Learn from Yields on Indexed Bonds?" Federal Reserve Board, FEDS working paper 2001-53, November 2001. 
[9] Brainard, William C., and George L. Perry. "Making Policy in a Changing World." In: George L. Perry and James Tobin (eds.) Economic Events, Ideas, and Policies : The 1960's and After Washington, DC: Brookings Institution Press, 2000, 43-82.

[10] Braun, Steven. "Productivity and the NIIRU (and Other Phillips Curve Issues)." Board of Governors of the Federal Reserve System, Working Paper 34, 1984.

[11] Brayton, Flint and David Reifschneider. "U.S. Macroeconomic Performance Since the Mid-1990s: The FRB/US View," Manuscript, Federal Reserve Board, April 2001.

[12] Campbell, John Y. "Inspecting the Mechanism: An Analytical Approach to the Stochastic Growth Model." Journal of Monetary Economics 33(3), June 1994, 463506.

[13] Christiano, Lawrence J., Martin Eichenbaum, and Robert Vigfusson. "What Happens After a Technology Shock?" Board of Governors of the Federal Reserve, International Finance Discussion Papers 768, June 2003a.

[14] Christiano, Lawrence J., Martin Eichenbaum, and Robert Vigfusson. "The Response of Hours to a Technology Shock: Evidence Based on Direct Measures of Technology." Board of Governors of the Federal Reserve, International Finance Discussion Papers 790, June 2003b.

[15] Clark, Peter K. "Capital Formation and the Recent Productivity Slowdown." The Journal of Finance 33(3) June 1978, 965-975.

[16] Congressional Budget Office. The Budget and Economic Outlook. Washington DC: Government Printing Office, various years.

[17] Congressional Budget Office. "CBO's Method for Estimating Potential Output." CBO Memorandum, October 1995.

[18] Council of Economic Advisors. it Economic Report of the President. Washington, DC: Government Printing Office, various years.

[19] Croushore, Dean. "Introducing: The Survey of Professional Forecasters." Federal Reserve Bank of Philadelphia Business Review November/December 1993, 3-13. 
[20] Cummins, Jason G., and Giovanni L. Violante. "Investment-Specific Technological Change (1947-2000)." Review of Economic Dynamics 5(2) April 2002, 243-284.

[21] Denison, Edward F. Accounting for Slower Economic Growth: The United States in the 1970s. Washington, DC: The Brookings Institution, 1979.

[22] Edge, Rochelle, Thomas Laubach, and John C. Williams. "Monetary Policy and the Effects of a Shift in the Growth Rate of Technology." Federal Reserve Bank of San Francisco, manuscript, 2003.

[23] Fletcher, C. A. J. Computational Galerkin Methods . New York: Springer-Verlag, 1984.

[24] Francis, Neville, and Valerie A. Ramey. "Is the Technology-Driven Real Business Cycle Hypothesis Dead? Shocks and Aggregate Fluctuations Revisited." University of California, San Diego, manuscript, December 2001.

[25] Galí, Jordi. "Technology, Employment, and the Business Cycle: Do Technology Shocks Explain Aggregate Fluctuations?" American Economic Review 89(1) March 1999, 249271.

[26] Gordon, Robert J. "Has the 'New Economy' Rendered the Productivity Slowdown Obsolete?" Northwestern University, mimeo, June 1999.

[27] Gordon, Robert J. "Does the 'New Economy' Measure up to the Great Inventions of the Past?" Journal of Economic Perspectives 14(4) Fall 2000, 49-74.

[28] Gordon, Robert J. "Exploding Productivity Growth: Context, Causes, and Implications." Brookings Papers on Economic Activity (2) 2003.

[29] Harvey, Andrew C. Forecasting, Structural Time Series Models and the Kalman Filter. Cambridge, UK: Cambridge University Press, 1989.

[30] Jorgenson, Dale W. and Kevin J. Stiroh "Raising the Speed Limit: U.S. Economiuc Growth in the Information Age." Brookings Papers on Economic Activity (1) 2000, $125-211$.

[31] Judd, Kenneth L. "Projection Methods for Solving Aggregate Growth Models," Journal of Economic Theory 58(2) December 1992, 410-452. 
[32] Kahn, James A, and Robert W. Rich. "Tracking the New Economy: Using Growth Theory to Detect Changes in Trend Productivity," Federal Reserve Bank of New York, mimeo, October 2003.

[33] Lansing, Kevin. "Learning about a Shift in Trend Output: Implications for Monetary Policy and Inflation." Federal Reserve Bank of San Francisco Working Paper 2000-16, January 2000.

[34] Laubach, Thomas, and John C. Williams. "Measuring the Natural Rate of Interest." The Review of Economics and Statistics 85(4) November 2003, 1063-1070.

[35] Nadiri, M. Ishag, and Sherwin Rosen. "Interrelated Factor Demand Functions." American Economic Review 59(4) September 1969, 457-471.

[36] Norsworthy, J. R., Michael J. Harper, and Kent Kunze. "The Slowdown in Productivity Growth: Analysis of Some Contributing Factors." Brookings Papers on Economic Activity (2) 1979, Washington, DC: The Brookings Institution, 387-421.

[37] Oliner, Stephen D., and Daniel E. Sichel "The Resurgence of Growth in the Late 1990s: Is Information Technology the Story?" Journal of Economic Perspectives 14(4) Fall $2000,3-22$.

[38] Orphanides, Athanasios. "Monetary Policy Rules Based on Real-Time Data." American Economic Review, 91(4) September 2001, 964-85.

[39] Pakko, Michael R. "Transition Dynamics and Capital Growth." Review of Economic Dynamics 5(2) April 2002, 376-407.

[40] Perry, George L. "Potential Output and Productivity." Brookings Papers on Economic Activity, (1) 1977, Washington, DC: The Brookings Institution, 11-60.

[41] Roberts, John M. "Estimates of the Productivity Trend Using Time-Varying Parameter Techniques." Contributions to Macroeconomics, 1(1) 2001, 1-27.

[42] Stock, James, and Mark Watson. "Median Unbiased Estimation of Coefficient Variance in a Time-Varying Parameter Model." Journal of the American Statistical Association, 93(441), March 1998, 349-358. 


\section{Appendix}

Table A1 reports the time series of the real-time Kalman filter estimates of trend labor productivity growth, as well as estimates from the CBO, CEA, and the median and mean values from the SPF. The first three columns show the real-time Kalman filter estimates using output per hour in the nonfarm business sector as the measure of labor productivity; columns four through six show the corresponding results for the total business sector (including farms). In each case, the value of the gain $\lambda$ is indicated at the top of the column. The real-time data set of output per hour in the nonfarm and total business sectors is available from the authors.

Starting with the 1997 Budget and Economic Outlook report, the CBO has each year reported their long-run projection for output per hour in the nonfarm business sector. These reports are generally published in January. We take the average projected rate of productivity growth over the next 11 years to be the trend rate. In year prior to 1997, generally no explicit figure for projected nonfarm labor productivity is given. For the 1995 and 1996 vintages, we inferred values of projected long-run productivity growth from the reported assumptions regarding projected total factor productivity growth and the pace of capital accumulation included in January 1995 and December 1995 reports, respectively, using the formula given in the Congressional Budget Office (1995) memo.

The CEA reported estimates of trend output per hour in the entire economy economy during the 1970s. Starting in 1983, the ERP regularly reported medium-run projections of output per hour in the nonfarm business sector in each Economic Report of the President. The horizon for these projections varies between six and nine years, typically shorter than those of the CBO projections and the Survey of Professional Forecasters and are therefore not directly comparable.

The SPF started asking a question regarding the average rate of productivity growth over the next ten years in February, 1992. The question is asked in each February survey. The SPF is described in Croushore (1993). The SPF reports both the median and mean response from the surveys, as well as the number of respondents. The data are available at the web site: http: \\www.phil.frb.org \econ \spf \index.html. 
Table A1. Real-time Estimates of Trend Productivity Growth

\begin{tabular}{|c|c|c|c|c|c|c|c|c|c|c|c|}
\hline \multirow{3}{*}{$\begin{array}{c}\text { Data } \\
\text { Vintage }\end{array}$} & \multirow[b]{3}{*}{$\lambda:$} & \multicolumn{6}{|c|}{ Kalman Filter } & \multicolumn{4}{|c|}{ Published Estimates } \\
\hline & & \multicolumn{3}{|c|}{ Nonfarm Business } & \multicolumn{3}{|c|}{ Total Business } & \multirow[t]{2}{*}{$\mathrm{CBO}$} & \multirow[t]{2}{*}{ CEA } & \multicolumn{2}{|c|}{ SPF } \\
\hline & & 0.12 & 0.08 & 0.22 & 0.12 & 0.08 & 0.22 & & & Mean & Median \\
\hline 1965 & & 2.7 & 2.8 & 2.8 & 3.1 & 3.1 & 3.1 & & & & \\
\hline 1966 & & 2.8 & 2.8 & 2.9 & 3.2 & 3.2 & 3.2 & & & & \\
\hline 1967 & & 2.8 & 2.8 & 2.8 & 3.2 & 3.2 & 3.2 & & & & \\
\hline 1968 & & 2.6 & 2.7 & 2.5 & 3.1 & 3.1 & 2.9 & & & & \\
\hline 1969 & & 2.8 & 2.9 & 2.8 & 3.2 & 3.2 & 3.1 & & 2.5 & & \\
\hline 1970 & & 2.6 & 2.7 & 2.4 & 3.0 & 3.0 & 2.7 & & 2.8 & & \\
\hline 1971 & & 2.3 & 2.5 & 1.9 & 2.7 & 2.8 & 2.3 & & 2.8 & & \\
\hline 1972 & & 2.4 & 2.6 & 2.2 & 2.8 & 2.9 & 2.5 & & & & \\
\hline 1973 & & 2.7 & 2.7 & 2.8 & 2.9 & 3.0 & 2.9 & & & & \\
\hline 1974 & & 2.7 & 2.7 & 2.8 & 2.9 & 3.0 & 2.9 & & 2.4 & & \\
\hline 1975 & & 1.9 & 2.2 & 1.3 & 2.2 & 2.5 & 1.5 & & & & \\
\hline 1976 & & 1.7 & 2.0 & 1.2 & 2.0 & 2.3 & 1.4 & & & & \\
\hline 1977 & & 2.0 & 2.2 & 1.9 & 2.3 & 2.5 & 2.1 & & 2.1 & & \\
\hline 1978 & & 2.0 & 2.1 & 1.9 & 2.3 & 2.4 & 2.1 & & 2.1 & & \\
\hline 1979 & & 1.7 & 1.9 & 1.4 & 1.9 & 2.2 & 1.5 & & 1.5 & & \\
\hline 1980 & & 1.4 & 1.7 & 0.9 & 1.6 & 2.0 & 1.0 & & 1.5 & & \\
\hline 1981 & & 1.2 & 1.6 & 0.5 & 1.4 & 1.8 & 0.7 & & & & \\
\hline 1982 & & 1.3 & 1.6 & 0.8 & 1.5 & 1.8 & 0.9 & & & & \\
\hline 1983 & & 1.1 & 1.5 & 0.6 & 1.4 & 1.7 & 0.8 & & 2.1 & & \\
\hline 1984 & & 1.4 & 1.6 & 1.2 & 1.5 & 1.8 & 1.2 & & 1.8 & & \\
\hline 1985 & & 1.6 & 1.7 & 1.7 & 1.8 & 1.9 & 1.8 & & 2.0 & & \\
\hline 1986 & & 1.1 & 1.3 & 0.9 & 1.3 & 1.6 & 1.0 & & 2.1 & & \\
\hline 1987 & & 1.1 & 1.4 & 1.0 & 1.3 & 1.6 & 1.2 & & 1.9 & & \\
\hline 1988 & & 1.2 & 1.4 & 1.2 & 1.5 & 1.7 & 1.4 & & 1.9 & & \\
\hline 1989 & & 1.3 & 1.5 & 1.3 & 1.5 & 1.6 & 1.4 & & 1.9 & & \\
\hline 1990 & & 1.4 & 1.5 & 1.4 & 1.6 & 1.7 & 1.5 & & 1.8 & & \\
\hline 1991 & & 1.0 & 1.2 & 0.7 & 1.2 & 1.4 & 0.8 & & 1.8 & & \\
\hline 1992 & & 0.8 & 1.0 & 0.4 & 1.0 & 1.2 & 0.6 & & 1.4 & 1.64 & 1.50 \\
\hline 1993 & & 1.0 & 1.2 & 1.0 & 1.2 & 1.4 & 1.1 & & 1.4 & 1.75 & 1.50 \\
\hline 1994 & & 1.2 & 1.3 & 1.3 & 1.4 & 1.5 & 1.4 & & 1.5 & 1.73 & 1.50 \\
\hline 1995 & & 1.3 & 1.4 & 1.5 & 1.5 & 1.6 & 1.6 & 1.3 & 1.2 & 1.60 & 1.50 \\
\hline 1996 & & 1.2 & 1.3 & 1.0 & 1.3 & 1.5 & 1.1 & 1.2 & 1.2 & 1.52 & 1.50 \\
\hline 1997 & & 1.0 & 1.2 & 0.8 & 1.1 & 1.4 & 0.9 & 1.2 & 1.2 & 1.40 & 1.27 \\
\hline 1998 & & 1.2 & 1.3 & 1.1 & 1.3 & 1.4 & 1.2 & 1.5 & 1.3 & 1.53 & 1.50 \\
\hline 1999 & & 1.4 & 1.4 & 1.4 & 1.5 & 1.6 & 1.6 & 1.8 & 1.3 & 1.66 & 1.55 \\
\hline 2000 & & 1.9 & 1.9 & 2.1 & 2.0 & 2.0 & 2.2 & 2.3 & 2.0 & 2.37 & 2.40 \\
\hline 2001 & & 2.2 & 2.1 & 2.6 & 2.3 & 2.2 & 2.7 & 2.7 & 2.3 & 2.48 & 2.50 \\
\hline 2002 & & 2.0 & 1.9 & 2.2 & 2.1 & 2.1 & 2.3 & 2.2 & 2.1 & 2.23 & 2.10 \\
\hline 2003 & & 2.2 & 2.1 & 2.6 & 2.3 & 2.2 & 2.7 & 2.2 & 2.1 & 2.37 & 2.30 \\
\hline 2004 & & 2.6 & 2.4 & 3.2 & 2.7 & 2.5 & 3.3 & 2.2 & 2.1 & 2.58 & 2.50 \\
\hline
\end{tabular}

